\title{
Effect of persistence in soil of Sulfosulfuron on fababean, chickpea and lentil grown in rotation in semi-arid area
}

Hajjaj B*, El Oualkadi A*

${ }^{*}$ Regional Agricultural Research Center of Tangier, Morocco
Corresponding author. E-mail: h_badr15@yahoo.fr

\begin{abstract}
A trial was conducted in greenhouse during 2009-2010 growing season in Chaouia semi-arid area of Morocco in order to study effect of Sulfosulfuron persistence in soil on fababean, chickpea and lentil grown in rotation. Three food legumes were grown in greenhouse pots: fababean, chickpea and lentil. Food legumes seeds were sown in five filled with soil taken from a plot that had been treated the previous year with Sulfosulfuron. Results showed that the highest Sulfosulfuron phytotoxicity was observed on lentil recording $60.8 \%$ of phytotoxicity. Phytotoxicity observed on chickpea and fababean pots registered $41.6 \%$ and $37.6 \%$, respectively. Thus, intensive tillage is recommended to farmers of Chaouia semi-arid region of Morocco when fababean, chickpea and lentil crops are grown in rotation after cereals, which had been treated with Sulfosulfuron.
\end{abstract}

Keywords_persistence, soil, sulfosulfuron, chickpea, fababean, lentil, chickpea.

\section{INTRODUCTION}

Cereal and food legumes crops play an important role in the arid and semi-arid areas of Morocco. They are food basis for the majority of the population. Weeds remain a major problem to cereals and food legumes production in Morocco. The problem of herbicide residues in soil hinders farmers, limits their strategic choice of crop rotation, and eventually decrease their economic benefits. Many authors reported cases of phytotoxicity due to sulfosulfuron (Abdennadher \& Tanji, 2000; El Ghazi, 2003; Hamal, 2005). Sulfosulfuron is new herbicides used in cereal to control weed infestation (Ezzahiri, 2017). It belongs to sulfonylurea chemical family. Sulfosulfuron inhibits the plant enzyme acetolactate synthase (ALS), which is essential for the synthesis of branched-chain amino acids valine, leucine, and isoleucine. Inhibition of amino acid production leds to inhibition of cell division and causes plant death. Sulfosulfuron is a systemic, phloem and xylem mobile herbicide that is absorbed through leaves, and roots (Ezzahiri, 2017). Herbicides residues in soil could injure in some cases crops grown crops grown in rotations. Residual fate and persistence behavior of herbicide in soil is very complex involving several factors ( soil, rain off...etc.). This study aims the assessment of the phytotoxicity of Sulfosulfuron residues in soil on fababean, chickpea and lentil in semi-arid area of Morocco.

\section{MATERIAL AND METHODS}

A trial was conducted in greenhouse of INRA Settat of Morocco during 2009-2010 growing season in order to study the effect of Sulfosulfuron persistence in soil on fababean, chickpea and lentil grown in rotation. The experimental design was completely randomized designs with five replications. Three food legumes tested in greenhouse pots: fababean, chickpea and lentil. Food legumes seeds were sown in five pots filled with soil taken from a plot that had been treated the previous year with Sulfosulfuron herbicide at the rate of application of 19.95 $\mathrm{g} / \mathrm{ha}$. Soil physicochemical properties of the experimental site are shown in table 1 . Pots size was $(30 \mathrm{~cm} \mathrm{x} 30 \mathrm{~cm} \mathrm{x}$ $40 \mathrm{~cm}$ ). Observations concerned Visual rating of phytotoxicity on fababean, chickpea and lentil following a scale ranging from 0 to $100 \%$ (where $0 \%$ is no symptoms of phytotoxicity while $100 \%$ is a necrosis on the whole plant). Statistical analyzes were performed with IBM SPSS Statistics, version 21.0 using the analysis of variance (ANOVA).The differences among phytotoxicity means was compared by Tukey's test at $P=0.05$.

Table 1: Soil physicochemical properties of the experimental site

\begin{tabular}{cccccc}
\hline Clay\% & Loam\% & $\begin{array}{l}\text { Sand } \\
\%\end{array}$ & $\mathrm{pH}$ & $\begin{array}{l}\mathrm{CaCO} 3 \\
\%\end{array}$ & $\begin{array}{c}\text { Organic Matter } \\
\% \\
(0.2 \mathrm{~mm})\end{array}$ \\
\hline 52.1 & 25.3 & 22.6 & 7.9 & 13.6 & 2.54 \\
\hline
\end{tabular}




\section{RESULTS AND DISCUSSION}

Statistical analysis revealed significant differences between legume species (Table 1). Results in Table 1 showed that the highest Sulfosulfuron phytotoxicity was observed on lentil recording $60.8 \%$ of phytotoxicity. Phytotoxicity observed on chickpea registered $41.6 \%$. Phytotoxicity observed on fababean registered $37.6 \%$. There were no significant statistical differences between phytotoxicity registered on fababean and chickpea. Thus, Sulfosulfuron residues on soil were more phytotoxic to lentil than fababean and chickpea.

Table. 2 : Observed phytotoxicity of Sulfosulfuron residues in the soil on fababean, chickpea and lentil

\begin{tabular}{lc}
\hline \multicolumn{1}{c}{ Food legume } & Phytotoxicity de Sulfosulfuron \\
\hline Fababean & $37.4^{\mathrm{a}}$ \\
Chickpea & $41.6^{\mathrm{a}}$ \\
Lentil & $60.8^{\mathrm{b}}$ \\
\hline \multicolumn{1}{c}{$P \alpha=0.05$} & $<0.001$ \\
\hline
\end{tabular}

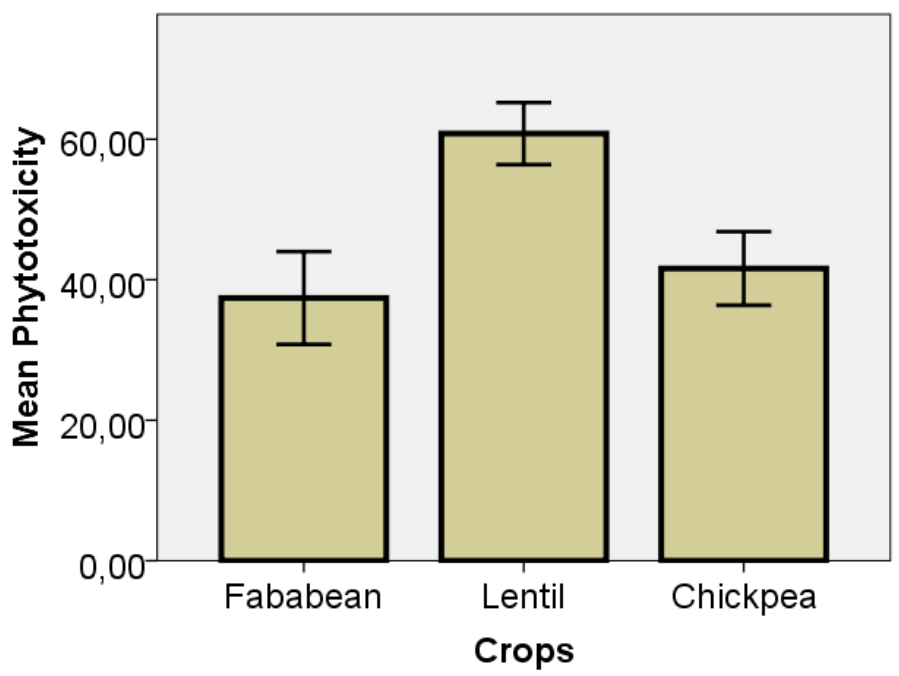

Error Bars: $95 \% \mathrm{Cl}$

Fig.1: Observed phytotoxicity of Sulfosulfuron residues in the soil on fababean, chickpea and lentil

Several factors influence impact of herbicide residues in soil on subsequent crops. Hens, same herbicide could behave differently from agro-climatic regions and soils. Some authors reported that dissipation of pesticide applied to the soil is a function of dispersion and degradation processes (Grébil, 2001). Dispersion is influenced by an association of transfer processes such volatilization, leaching, water runoff, and plant absorption. Whereas degradation is described by chemical reactions (photodecomposition, hydrolysis...etc.) or biochemical reactions involving soil microorganisms (Grébil, 2001). Bouhache (2018) had listed some measures to avoid the risk of phytotoxicity caused by herbicide residues. In fact, weed management in accordance with the principles of integrated management is an approach to achieve this aim. In addition, the choice of low-half-life herbicides and no risk of herbicide persistence on crops in rotation, the reduction of the recommended dose with equal efficacy, the mixing of two or more herbicides and the earliest possible application are measures that reduce the time of herbicides dissipation in the soil and save the subsequent crops from any adverse side effects. Frequent small irrigations is another possibility to increase chemical degradation of applied herbicides (Bouhache, 2018). In addition, respect of the the time required between the application of herbicides and next crops grown in rotation, indicated on the prospectuses of certain herbicides, is an element to be considered in this management. Thus, it is recommended to read the herbicide prospectus to be informed of the time interval between the application of herbicides and subsequent crops. Finally, it is important to mention that the use of tillage after harvesting is recommended to mix the treated and untreated soil layers and thus disperse the herbicide residues (Zaragoza, 2005, Bouhache, 2018).

\section{CONCLUSION}

This study has shown that the highest Sulfosulfuron phytotoxicity was observed on lentil recording $60.8 \%$ of phytotoxicity. Phytotoxicity observed on chickpea registered $41.6 \%$. Phytotoxicity observed on fababean registered $37.6 \%$. Intensive tillage is recommended to farmers of Chaouia region of Morocco when fababean, chickpea and lentil crops are grown in rotation after cereals, which had been treated with Sulfosulfuron. This study should be repeated in different sites and different soils for further assessment of Sulfosulfuron residues in soil and its phytotoxicity should be evaluated on other crops grown in rotations.

\section{ACKNOWLEDGMENT}

The authors are grateful to all technicians of INRA Sidi El Aidi Settat research station for providing necessary facilities for conducting this research work.

\section{REFERENCES}

[1] Abdennadher M. \& Tanji A. (2000). Sulfosulfuron persistence and rate response of durum wheat cultivars and rotational crops in North Africa. Proc. Journée nationale sur le désherbage des céréales, Settat, pp. 117-131.

[2] Bouhache M. (2018). Désherbage chimique des céréales, persistance des herbicides dans le sol et risque de phytotoxicité aux cultures suivantes. Agriculture de Maghreb No 114 . Pages : 78-81. 
[3] El Ghazi M. (2003). Effet résiduel de sulfosulfuron et de la métribuzine sur la croissance et le développement des légumineuses alimentaires. Mémoire de troisième cycle pour l'obtention du grade d'ingénieur d'état en agronomie, ENA Meknès. 111p.

[4] Ezzahiri B., Bouhache M. \& Mihi M. (2017). Index Phytosanitaire Maroc, 304p.

[5] Grébil G., Novak S., Perrin-Ganier C., Schiavon M. (2001). La dissipation des produits phytosanitaires appliqués au sol. Ingénieries 2001 - $\mathrm{N}^{\circ}$ Spécial Phytosanitaires. Pages : 3144.

[6] Hamal A. (2005). Elaboration des bases de gestion intégrée $\mathrm{du}$ brome raide (Bromus rigidus Roht.) dans la culture de blé (Triticum spp.) dans le Sais, Maroc. Thèse de Doctorat, IAV Hassan II, Rabat. 173p.

[7] IBM SPSS Statistics for Windows, Version 21.0. (2012). Armonk, NY: IBM Corp.

[8] Zaragoza C. (2005).La gestion des mauvaises herbes dans les cultures maraîchères. In Gestion des mauvaises herbes pour les pays en développement. Labrada . eds. Pages : 151-164. 